\title{
Study on new viscosity modifying agents
}

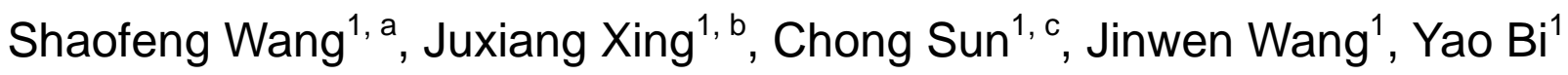 \\ ${ }^{1}$ China Construction Ready Mixed Concrete Co. Ltd, Wuhan 430205, China \\ aemail: jaylia08@hotmail.com, ${ }^{\mathrm{b} e m a i l}$ :xingjuxiang@126.com, ${ }^{\mathrm{c} e m a i l:}$ 253186118@qq.com
}

Keywords: Viscosity modifying agent; fluidity; free radical polymerization; yield stress; apparent viscosity; fresh concrete.

\begin{abstract}
In this work, we synthesized a new viscosity modifying agents with AA, AM as monomer and ammonium persulfate as initiator. Through the discussion on the AA dosage, the polymerization conditions, we determined the optimum technological conditions of the new VMA: the optimum molar ratio of AA to AM is $1: 1$, the dosage of initiator is $2 \mathrm{wt} \%$ of all the monomers. The optimum polymerization time is $3 \mathrm{~h}$ at $65^{\circ} \mathrm{C}$.The new VMA can significantly improve yield stress and apparent viscosity of cement paste.
\end{abstract}

\section{Introduction}

With the development of construction technology, commercial concrete is gradually asked higher slump and bigger flow direction, which can realize the remote pumping and let fresh concrete through more intensive steel regions. But the fluidity and cohesiveness of the fresh concrete are usually contradictory $^{[1]}$. if the mixture with low viscosity, segregation is easy to occur in concrete, especially continuous deterioration of the concrete raw materials and high sensitivity of the polycarboxylate superplasticizers, which make this problem more prominent .

There are two methods to solve the segregation of high flowing concrete: One method to achieve high flowing concrete property is increasing the amount of fine materials (e.g., fly ash or limestone filler) ${ }^{[2]}$ significantly, without changing the water content. The other alternative approach is adding a viscosity modifying agents (VMA) to enhance stability ${ }^{[3,4]}$. Using VMA along with adequate concentration of superplasticizers can ensure high deformability and adequate workability of fresh concrete, also can ensure a good resistance to segregation.

Using Cellulose ether and Welan gum as VMA have proved very effective ${ }^{[5-7]}$, But they always retard Portland cement hydration severely, also Welan gum is expensive.

In this paper, we used Acrylamide, Acrylic acid as monomers to synthesize a new viscosity modifying agents by free radical copolymerization, the new VMA has good compatibility with Polycarboxylate Superplasticizers and other concrete admixtures, also it can significantly improve yield stress and apparent viscosity of cement paste with no air entraining.

\section{Materials and methods}

\subsection{Raw materials}

Acrylic acid (AA), Ammonium Persulphate (APS), Thioglycollic acid (TGA), Acrylamide(AM) and sodium hydroxide $(\mathrm{NaOH})$ are purchased from Sinopharm Chemical Reagent Co., Ltd. Polycarboxylate-type (PCE) superplasticizers is obtained from China Construction Ready Mixed Concrete Co. Ltd.

\subsection{Synthesis of the samples}

Using AA, AM as monomers, free radical polymerization proceeded in aqueous solution. The initiator used here is ammonium persulfate. After samples cooled to room temperature, the $\mathrm{NaOH}$ solution is used to regulated the $\mathrm{pH}$ to $7 \sim 9$.

\subsection{Characterization and evaluation of samples}

Nicolet AVATAR 370-Fourier Transform Infrared Spectrometer (US) is used to analysis samples structure.

Molecular weights (Mw, Mn) of synthesized samples are determined by gel permeation 
chromatography (GPC) using $0.15 \mathrm{~mol} / \mathrm{L}$ buffer solution of phosphoric acid as a mobile phase at a flow rate of $1.0 \mathrm{~mL} / \mathrm{min}$.

The apparent viscosity of 1\% VMA solution are determined by NDJ-5S rotational viscometer with rotor 4 , test temperature is $22 \sim 25^{\circ} \mathrm{C}$, Shear velocity is $12 \mathrm{R} / \mathrm{min}$.

Paste fluidity test is carried out according to GB 8077-2000 "Methods for Testing Uniformity of Concrete Admixture". The cement used for the test is HUAXIN P•O 42.5, the w/c ratio is 0.29, the dosage of the PCE is $0.2 \mathrm{wt} \%$ (the percent mass to cement) and the dosage of VMA is $0.02 \mathrm{wt} \%$.

When the fluidity of cement paste is less than $220 \mathrm{~mm}$, the influence of surface tension can be neglected, the yield stress can be calculated by the cement paste fluidity through the formula $(2-1)^{[8]}$.

$$
\tau_{0}=\frac{225 \rho \cdot g \cdot v^{2}}{128 \pi^{2} \cdot R^{5}\left(1+\frac{225}{128 \pi} \sqrt{3} \cdot v \cdot R^{-3}\right)}
$$

( $\rho$ : Paste density; v: Paste volume; g: the acceleration of gravity; R: Fluidity radius)

\section{Results and discussion}

\subsection{The molar masses and polydispersities of VMA}

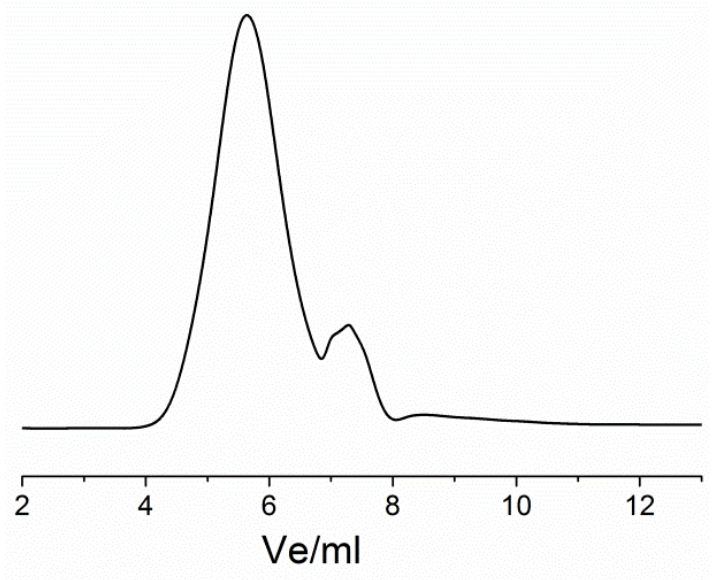

Fig. 1 molecular weight distribution of VMA

As can be seen from Figure 1, the average Molecular Weight of VMA is up to 500,000, which can improve VMA's viscous effect due to the relationship between molecular weight and Viscous effect.The plot of molecular weight and molecular weight distribution (MWD) of the VMA was shown in Table1 and Figure 1.

Table 1 The molar masses and polydispersities of VMA

$\begin{array}{cccc}\text { sample } & \mathrm{M}_{\mathrm{n}}(\mathrm{g} / \mathrm{mol}) & \mathrm{M}_{\mathrm{w}}(\mathrm{g} / \mathrm{mol}) & \mathrm{MWD} \\ \text { VMA } & 183482 & 506748 & 2.76\end{array}$

\subsection{Effect of polymerization temperature on the performance of VMA}

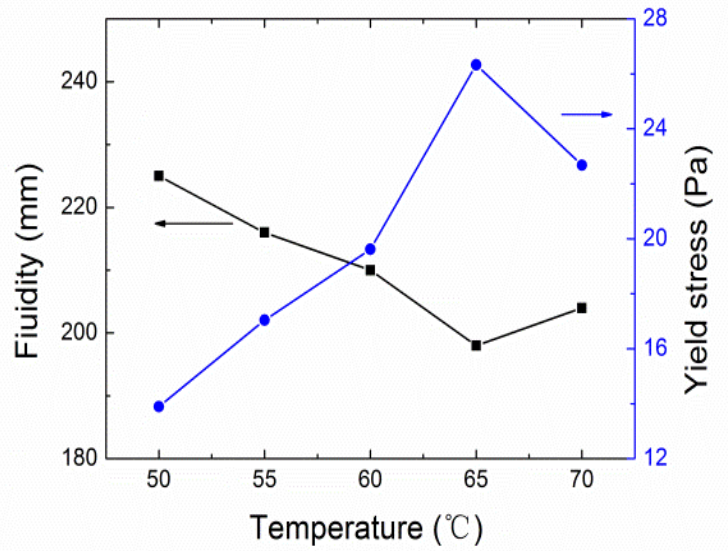

Fig.2 temperature effect on the performance of VMA

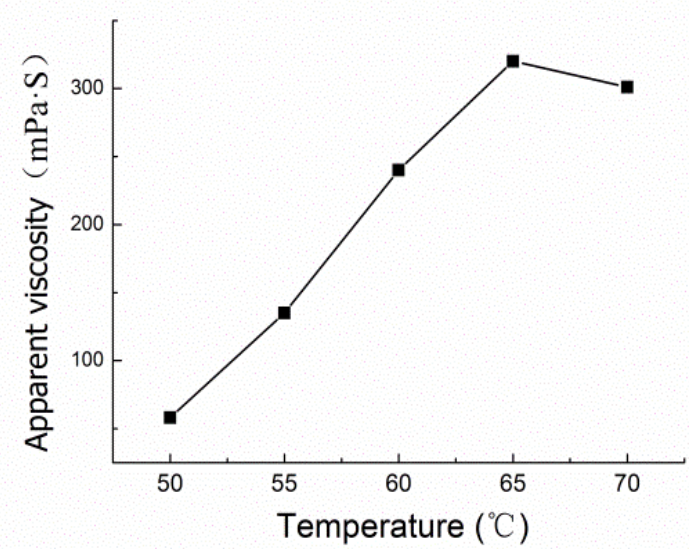

Fig.3 temperature effect on the apparent viscosity of VMA 
With the increase of reaction temperature, the yield stress of cement paste and the apparent viscosity of VMA solution increased gradually, we got the maximum data at $65^{\circ} \mathrm{C}$. But the yield stress will decrease if increasing the reaction temperature sequentially, mainly because initiator decomposition rate is too fast at high polymerization temperature, which results in lacking late initiation efficiency.

\subsection{Effect of initiator dosage on the performance of VMA}

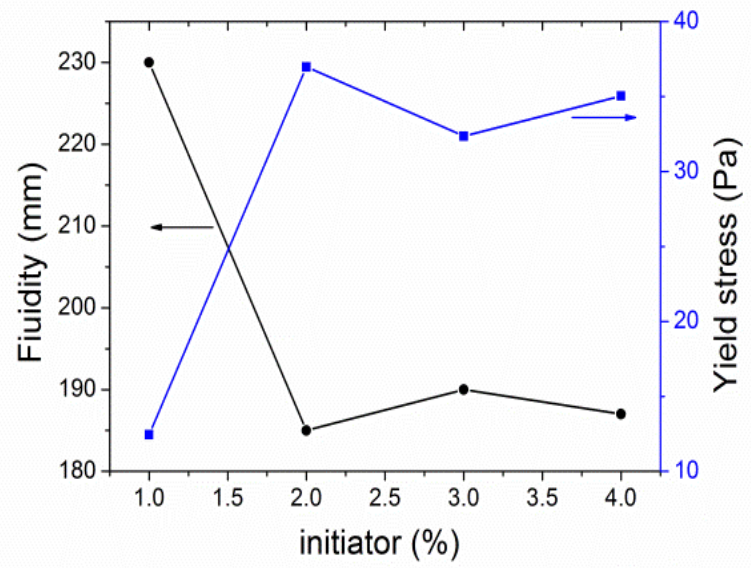

Fig.4 initiator effect on the performance of VMA

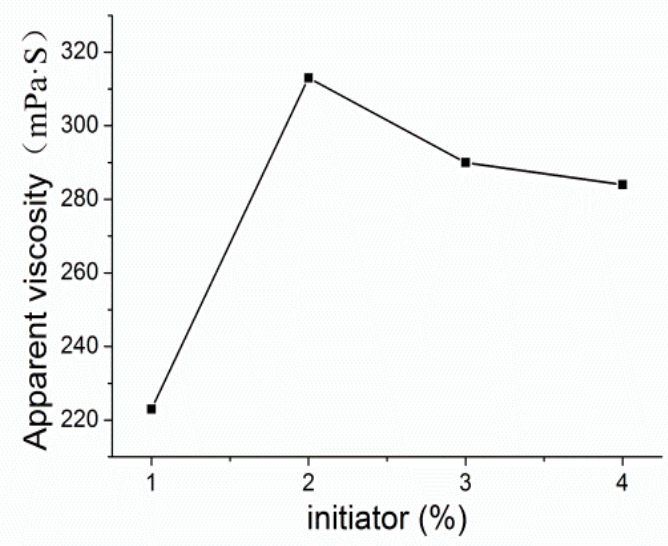

Fig.5 initiator effect on the apparent viscosity of VMA

As can be seen from the Figure 4 and Figure 5 :when the ammonium persulfate mass is $1 \%$ of all monomers, the polymerization system has viscosity, but the slurry yield stress does not increase obviously, which indicates the monomer can react with low conversion rate at this time. With the increase of initiator dosage, monomer conversion rate gradually increased, product viscosity improved too. When the initiator dosage up to $2 \mathrm{wt} \%$, the monomer can react completely, the product get the best performance .

\subsection{Effect of AA content on the performance of VMA}

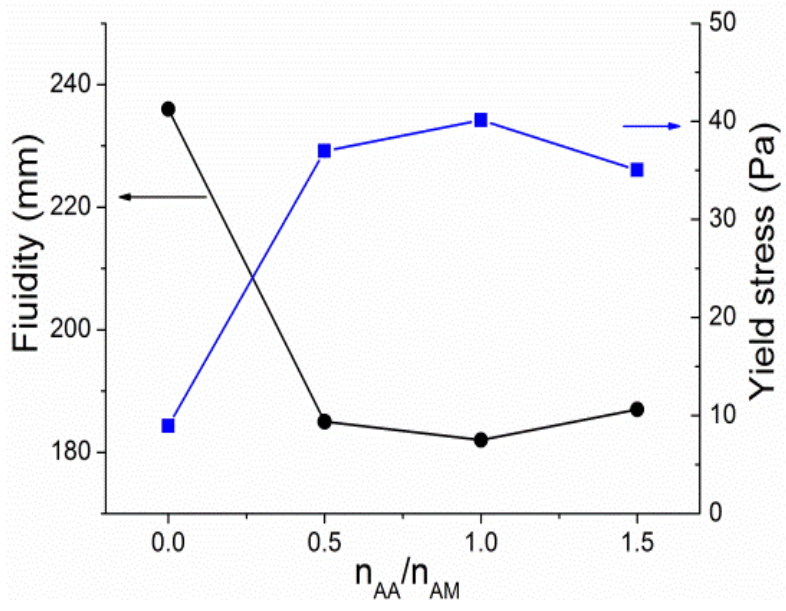

Fig.6 Effect of AA content on the performance of VMA

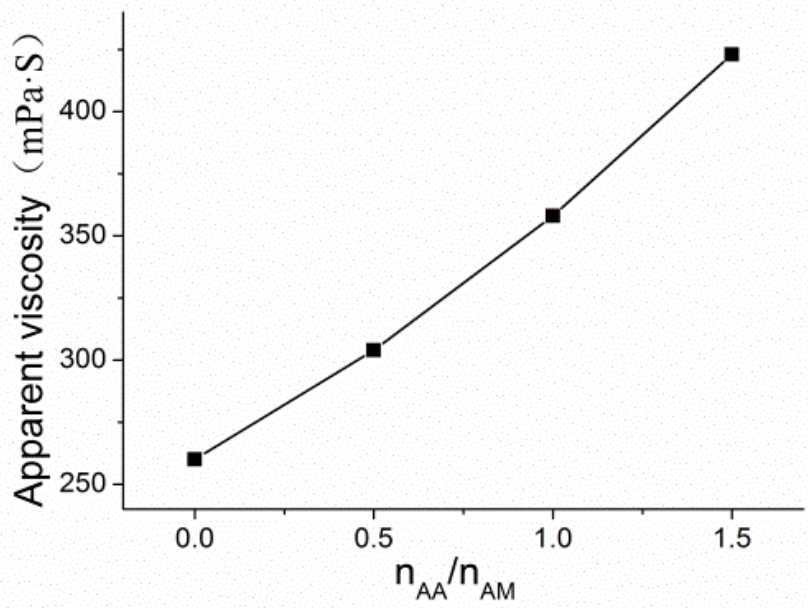

Fig.7 Effect of AA content on the apparent viscosity of VMA

As can be seen from Figure 6 and Figure 7: without adding Acrylic acid, the VMA improved the yield stress of cement paste slightly, With the increase of AA content, the yield stress of cement paste significantly increased before $\mathrm{n}_{(\mathrm{AA})} / \mathrm{n}_{(\mathrm{AM})}=0.5$, probably because the polymer adsorption on cement particles is enhanced by increasing Carboxyl density, VMA's apparent viscosity increases significantly with the increase of AA content too.

\section{Conclusions}

Through the discussion on AA content and the polymerization conditions, we determined the 
optimum conditions to synthesis the new VMA: the optimum molar ratio of AA to AM is $1: 1$, the dosage of initiator is $2 \mathrm{wt} \%$ of all the monomers. The optimum polymerization time is $3 \mathrm{~h}$ and the optimum reaction temperature is $65^{\circ} \mathrm{C}$, the average molecular weight of VMA can up to 500,000.

\section{References}

[1] J. Plank, Applications of biopolymers in construction engineering, in: A. Steinbüchel (Ed.), Biopolymers, Wiley-VCH, Weinheim (2003),p. 29-95

[2] H. Lutz, R. Bayer, Dry mortars, Ullmann's Encyclopedia of Industrial Chemistry,Wiley-VCH Verlag GmbH \& Co. KGaA, Weinheim(2010), p. 1-41

[3] J. Pourchez, P. Grosseau, B. Ruot, Current understanding of cellulose ethers impact on the hydration of C3A and C3A-sulphate systems, Cem. Concr. Res. 39 (2009), p664-669

[4] J. Pourchez, A. Peschard, P. Grosseau, R. Guyonnet, B. Guilhot, F. Vallée, HPMC and HEMC influence on cement hydration, Cem. Concr. Res. 36 (2006),p. 288-294

[5] H. Thielking, M. Schmidt, Cellulose ethers, Ullmann's Encyclopedia of Industrial Chemistry, Wiley-VCH Verlag GmbH \& Co. KGaA, Weinheim(2006), p. 1-18

[6] D. Bülichen, J. Kainz, J. Plank,Working mechanism ofmethyl hydroxyethyl cellulose(MHEC) as water retention agent, Cem. Concr. Res. 42 (2012),p. 953-959

[7] W. Burchard, Solubility and solution structure of cellulose derivatives, Cellulose10 (2003), p.213-225

[8] J. Zimmermann, C. Hampel, C. kurz, Effect of polymer structure on the sulphatepolycarboxylate competition, 5th CANMET/ACI International Conferenc on Superplasticizers and Other Chemical Admixtures in Concrete, ACI SP. 173 